
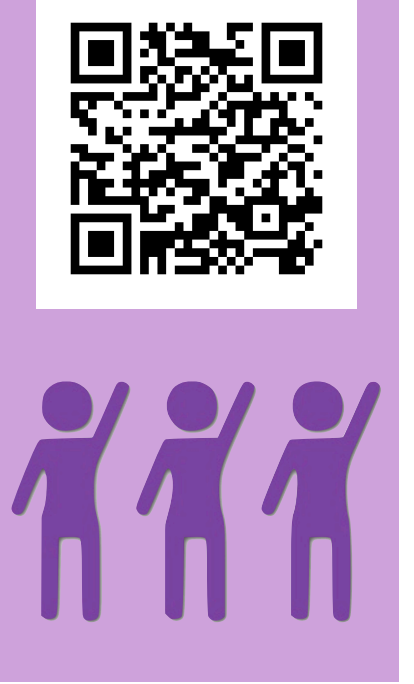

\title{
Interseccionalidades de raça, gênero, machismo e sexismo na literatura insurgente de Lima Barreto
}

\section{Edergênio Negreiros VIEIRA, Universidade Estadual de Goiás}

Esse texto é uma viagem literária, musical, pop, idiossincrática e sub-reptícia por um caminho perscrutador das minhas subjetividades como homem, negro, professor, morador de periferia e militante social com duas obras literárias do escritor Lima Barreto: "Clara dos Anjos" e "Recordações do Escrivão Isaías Caminha" e as interseccionalidades de raça, gênero, machismo e sexismo presentes nos romances. Faço isso com a ajuda de Kilomba (2019), Beauvoir (1980), hooks (1989), Cândido (1995), Fanon (2008), Freud (1995), entre outras/os. Busco situar a literatura limabarretiana no campo das literaturas insurgentes, como escritas que rompem com o canônico, com o paradigmático e insurgem contra os dogmas vigentes. Escrita insurgente, este artigo coloca-se como desafio construir novas possibilidades transgressivas e insurgentes na escrita acadêmica; por isso, opto por configurá-lo numa linguagem caleidoscópica e intersecionada, analisando e problematizando vários temas que se fragmentam nos recortes específicos e que se unem para formar um todo que representa a própria unidade idiossincrática dos sujeitos e das "sujeitas" presentes nos referenciais teóricos que ancoram o texto. As partes do ensaio compõem o todo e o todo compõe as partes; assim, a escritura funciona como um fluxo de pensamento em que não há um início e nem um fim, uma conclusão e sim um debate num momento específico, que não começa e nem termina nesse texto. Insiro no corpo do escrito os links das músicas citadas para que o/a leitor/a experimente uma leitura semiótica da investigação, intercalando a leitura com a escuta/visão das/dos músicas/clips. As seções do texto são nomeadas com letras de rap que guardam relação com o assunto a ser debatido naqueles espaços.

PALAVRAS-CHAVE: Literatura. Racismo. Machismo. Sociedade. 


\section{Eu pastorei a negra ovelha que vagou dispersa. Polinização pauta a conversa. Até que nos chamem de colonização reversa (EMICIDA, 2019)}

A escrita acadêmica, nomeio aqui de forma sub-reptícia escrita acadêmica, sendo aquela que se coloca dentro de um gênero textual específico, exige alguns elementos que a caracterize. Este ato de escrita, sobretudo em ambientes acadêmicos, e uma revista científica constitui a extensão desses lugares acadêmicos, como a universidade, seminários, colóquios, é constantemente monitorado e leva em conta aspectos como impessoalidade, objetividade, além da excessiva valorização da norma padrão que rege o português brasileiro. São preceitos e protocolos que, em alguns casos performáticos são ratificados muitas das vezes sem reflexão por parte de quem escreve, acerca do real sentido dessa produção escrita. Essa forma de escrever traz como projeto implícito o apagamento das especificidades do autor ou da autora e, quando esse/a se posiciona na escrita, tem o seu texto geralmente nomeado como lírico, poético ou subjetivo demais para ser escrita acadêmica. Muitos/as autores/as, aqui destaco Makoni e Pennycook (2007), ressaltam o processo de colonização epistêmica que existe por trás desses discursos hegemônicos que visam o apagamento do sujeito que escreve. Perceba então que há uma forma de escrever tida como hegemônica na academia e quem se afasta dela corre o risco de ser nomeado/a como não acadêmico/a. Por isso é preciso apropriar dessa forma legitimada de escrever, conforme aponta Pennycook (2006), para propor um contradiscurso. Escrever para um/a pesquisador/a é tarefa indispensável: eu leio, pesquiso, reflito e escrevo. Kilomba (2019) evidencia que escrever é um ato político. E como ato político, a escrita não deve ser invisibilizada e nem silenciada. Digo isso pois acredito que, em alguns casos, há uma tentativa organizada de retirar a identidade do/ a autor/a dos textos escritos. A academia ainda é um lugar excessivamente grafocêntrico. Sendo assim, uma das possibilidades de provocar insurgências no ambiente acadêmico e de provocar fissuras epistemológicas é subverter as implicações do gênero textual artigo científico. Certeau (1998) aponta que a escritura é uma forma de hierarquização social que sempre privilegiou o burguês no passado, e hoje privilegia o tecnocrata. De acordo com ele, a escritura é a lei de uma educação sistematizada, pela classe social dominante, que pode fazer da 
linguagem, seja matemática ou retórica, o seu instrumento de produção e de reprodução das hierarquizações sociais, políticas, culturais e históricas.

Na Ideologia Alemã, Marx e Engels (2002, p. 37) apontam que "[n]ão é a consciência que dertemina a vida, mas a vida que determina a consciência"; a formação dessa consciência advém das experiências de vida, e essas vivências constituem o sujeito da escrita ou da fala. Somos seres de linguagem.

A linguagem é tão antiga quanto a consciência, a linguagem é a consciência real, prática que existe para os outros homens e, portanto, existe também para mim mesmo; e a linguagem nasce, como a consciência, da carência da necessidade de intercâmbio com outros homens. (MARX; ENGELS, 2002, 43)

E eles prosseguem (MARX; ENGELS, 2002, p. 43): “[a] consciência portanto é desde o início um produto social, e continuará sendo enquanto existirem homens." Por isso, toda enunciação tem um sentido político. É enunciada por um sujeito específico e não por outro/ a. Esse sujeito pertence a uma classe social, a um gênero, a uma orientação sexual, a uma raça; ele/a enfim é um sujeito político. Sendo assim, é preciso dotar a escrita de sentido que não termina no texto, e sim que o tenha como auxiliar do/a intelectual para inserir fissuras epistêmicas no concreto canônico dos círculos acadêmicos, especialmente. Escrever é situar o ser social e ontológico no hic et nunc da existência; nesse exercício, vem à tona a imaginação, as memórias, as vivências, a vida que acontece lá fora, a chuva que cai, a tarde que chega, e o/a intelectual se isola, mesmo que por alguns instantes, para fazer surgir os períodos do ato enunciativo. São conflitos, preocupações e lembranças que surgem e que pululam no texto.

Lembro-me de bell hooks (1989) que aponta dois conceitos: sujeito e objeto. Ela argumenta que os sujeitos podem determinar suas realidades essenciais. Eles/as estabelecem suas identidades de forma autônoma e, assim, nomeiam suas histórias. Ao contrário do objeto, a pesquisadora diz que aquele que não pode ser nomeado, ele/eles é/são definido/s pelo Outro; logo, as identidades também são criadas por esse Outro. Assim, a minha relação com a história não é definida por mim, e sim pelo sujeito que me analisa, que "em vez de tirar, universidade me cata, sou fonte de estudo pra faculdade babaca." (FLORA MATOS, 2011.) (https://www.youtube.com/watch?v=92jEmOnilMQ). Nesse sentido, Kilomba afirma: 
Essa passagem de objeto a sujeito é que marca a escrita como um ato político. Além disso, escrever é um ato de descolonização no qual quem escreve se opõe a posições coloniais tornando-se a/o escritora/ escritor "validada/o" e legitimada/o e, ao reinventar a si mesma/o, nomeia uma realidade que fora nomeada erroneamente ou sequer fora nomeada. (KILOMBA, 2019, p. 28).

Pensando e problematizando todas essas questões levantadas nesse prólogo, o texto tem como objetivo posicionar a literatura do escritor brasileiro Lima Barreto numa posição de escrita insurgente contra o racismo, o machismo e o sexismo e suas consequências na sociedade brasileira, por meio de uma investigação bibliográfica, subjetiva e subversiva da obra do autor de "Clara dos Anjos", "Recordações do Escrivão Isaías Caminha”, entre outros.

A insurgência no ato de escrever visa ser a representação escrita de quem eu sou, como sujeito da minha própria história e opor-se às formas legitimadas de escrita acadêmica. Portanto, no texto pululam as minhas idiossincrasias de homem, negro, morador de periferia, professor, pai, filho, neto, militante social do movimento em defesa dos direitos humanos. São essas identidades que se intercruzam com os textos teóricos, filosóficos, literários e dialetizam insurgências e transgressões na tessitura do artigo.

Essa é uma posição política que o texto assume, ciente das dificuldades que isso impõe, sobretudo, em processos hierarquizados e tão normatizados e regulados como é o espaço da universidade e do gênero textual ratificado na academia. Ou seja, da escrita nomeada como acadêmica, mas é preciso repensar o sentido dessa escrita. Refletir sobre e problematizá-la são os primeiros passos, não para mudá-la, numa posição de paradigma, mas sim para situar a corporiedade que se reflete no texto, a parcialidade que subjaz a escrita e as subjetividades adjacentes as corporeidades epistêmicas no universo acadêmico.

Com relação ao sujeito preto, a francesa Simone de Beauvoir evidencia:

É sempre difícil ser um recém-chegado que tenta abrir caminho através de uma sociedade hostil ou, pelo menos, desconfiada. Richard Wright mostrou, em Black Boy, a que ponto as ambições de um jovem negro nos Estados Unidos são barradas desde o início e que luta lhe cabe sustentar simplesmente para erguer ao nível em que os problemas começam a apresentar-se aos brancos; os negros que vieram da África para a França conhecem também - em si mesmos 
como exteriormente - dificuldades análogas. (BEAUVOIR, 1980, p. 467).

A universidade é em si um terreno hostil à estética do sujeito preto. A sociedade é hostil à presença do/a preto/a em espaços sociais de prestígio. E mesmo estando nesses espaços,

80 tiros te lembram que existe pele alva e pele alvo, quem disparou usava farda (mais uma vez) quem te acusou nem lá num tava (bando de espírito de porco), porque um corpo preto morto é tipo os hit das paradas, todo mundo vê mas essa porra não diz nada (EMICIDA, 2019. https://www.youtube.com/watch?v=4pBp8hRmynI).

\section{Sou antigo na arte de nascer das cinza, tanto quanto um bom motorista, é na arte de fazer baliza, eu tô na arte de fazer. (DJONGA, 2019)}

Para continuar o nosso diálogo, quero justificar a escolha do título desse texto e, para fazê-lo, vou partir do conceito, ou melhor, dos conceitos impressos nas palavras do título. Para Deleuze e Guattari (2010, p. 8), "os conceitos como veremos tem necessidade de personagens conceituais que contribuam para sua definição.” A definição do que é interseccionalidade foi pensada a partir do movimento do feminismo negro. Carla Akotirene, na obra "O que é interseccionalidade?”, pensou-a como uma categoria teórica que teve como lugar de reflexão múltiplos sistemas de opressão, no caso, conectando raça, gênero e classe. Akotirene (2018, p. 54) afirma que a interseccionalidade:

demarca o paradigma teórico e metodológico da tradição feminista negra, promovendo intervenções políticas e letramentos jurídicos sobre quais condições estruturais o racismo, seximo e violências correlatas se sobrepõem, discriminam e criam encargos singulares às mulheres negras.

Pensando a partir do conceito formulado por Akotirene (2018), a interseccionalidade visa contribuir para o entendimento sobre as disparidades raciais que existem. Akotirene (2018, p. 56) afirma que "racismo, capitalismo, hétero-patriarcado devem ser tratados pela interseccionalidade, observando os contornos identitários da luta antirracista diaspórica." Já com relação à palavra raça, faço um recorte fundamental para o entendimento do texto: raça é pensada aqui como 
uma categoria social, histórica e cultural. Raça é um dos conceitos mais espinhosos para se situar quando se pensa na espécie humana, que biologicamente é representada pelo homo sapiens. Mas raça nesse texto será pensada pelo viés construído ao longo dos anos, que foi fundamental para se instituir a tecnologia do racismo. Sim, nomeio racismo aqui na definição de Mbembe (2018, p. 18, destaque do autor), quando esse afirma,

Que a "raça (ou, na verdade, o "racismo") tenha um lugar proeminente na racionalidade própria do biopoder é inteiramente justificável. Afinal de contas, mais do que o pensamento de classe (a ideologia que define história como uma luta econômica de classes), a raça foi a sombra sempre presente no pensamento e na prática das políticas do Ocidente, especialmente quando se trata de imaginar a desumanidade de povos estrangeiros - ou a dominação a ser exercida sobre eles.

A raça foi usada como elemento definidor de humanidade. A chegada do processo "civilizatório" europeu, racializou o branco e desracializou os povos indígenas, assim como os africanos que foram usados como força de trabalho escrava nas plantações de açucar e café. As pessoas negras e as indígenas foram acusadas de não terem "alma" e também foram comparadas a animais irracionais. Obviamente havia um sentido nessa desumanização de indígenas e negros/as. Mbembe destaca que "com efeito, em termos foucaultianos, racismo é acima de tudo uma tecnologia destinada a permitir o exercício do biopoder, "este velho direito soberano de matar." (MBEMBE, 2018, p. 18, destaque do autor). Foi sob o discurso de raça que os brancos mataram milhões de indígenas e africanos/as.

Além da raça, outra formulação presente neste texto é o conceito de gênero. A visão que marca a ideia de gênero nessa exposição pertence a Beauvoir (1980) que diz que uma coisa é o sexo biológico, o qual está fundamentalmente relacionado aos fatores físico-químicos do corpo humano, já o gênero é também uma categoria social, histórica e cultural. Em outras palavras, quando eu falo "gênero feminino" estou me referindo ao que se associou a essa condição do ser feminino. Assim, é possível afirmar que, olhando desse lugar, gênero é um constructo social. $\mathrm{E}$, por fim, machismo e sexismo que se referem às práticas presentes na sociedade brasileira, sendo que o primeiro parte da ideia de que exista uma superioridade masculina em relação às mulheres, e se expressa em piadas, brincadeiras, ditados populares, lugares-comuns ratificados por inúmeras instituições sociais; e o segundo consiste na crença de que 
existem funções que são destinadas apenas a um ou outro gênero sexual. Por exemplo, o homem é mecânico e a mulher enfermeira. O sexismo se expressa, entres outras formas, por meio de preconceitos como esses.

\section{Entre o Machado de Assis e de Xangô. Soneto de boêmia, poesia, melancolia, Eu sou do tempo onde poetas ainda faziam poesia. Saravá (BACO EXU DO BLUES, 2017)}

A literatura é uma das formas que o ser humano encontrou de projetar o seu eu no mundo. Desde os primórdios da (ir)racionalidade humana, o homem adquiriu a possibilidade de criar selfs e por meios dessas, construir e constituir imaginários sociais que, ao serem projetados e introjetados, tornam-se reais. Assim, um simples caso que deveria ser exceção, torna-se a regra, e tem-se a inversão da realidade, onde a exceção vira regra, e a regra exceção. Candido afirma:

A literatura tem sido um instrumento poderoso de instrução e educação, entrando nos currículos, sendo proposta a cada um como equipamento intelectual e afetivo. Os valores que a sociedade preconiza, ou os que considera prejudiciais, estão presentes nas diversas manifestações da ficção, da poesia e da ação dramática. A literatura confirma e nega, propõe e denuncia, apoia e combate, fornecendo a possibilidade de vivermos dialeticamente os problemas (CANDIDO, 1989, p. 113)

A literatura é o sonho acordado da civilização e, por meio dela, constituímos e somos constituídos; a literatura é indispensável para a constituição do ser humano, marcado pelo desenvolvimento do signo linguístico e semiológico como um todo. Beauvoir evidencia:

a literatura assume seu estilo e dignidade quando se endereça a indivíduos empenhados em projetos, quando os ajuda a se ultrapassarem para horizontes mais amplos; cumpre que ela seja integrada ao movimento da transcendência humana. (BEAUVOIR, 1980, p. 360)

Uma das perspectivas de integrar a literatura à transcendência humana e o entendimento sobre a perspectiva da literatura insurgente e suas interseccionalidades de raça e classe social em Lima Barreto é o romance inaugural da obra desse escritor. "Recordações do Escrivão Isaías Caminha" (1956) é a intersecção entre a vida da personagem e a 
existência do próprio autor. As personagens principais de Lima Barreto são, por vezes, a representação do alter ego do escriba. "Recordações do Escrivão Isaías Caminha" (1956) expressa bem essa intertextualidade do escrito literário: a realidade vira ficção e a ficção torna-se realidade no desenrolar do enredo e da relação da personagem com os albores da República brasileira.

Preto e pobre, Lima Barreto viveu na pele a dificuldade em ser negro no Brasil. Ele viu nos estudos uma possibilidade de superar essa condição social. Porém teve que abandonar a aprendizagem de Engenharia para trabalhar como escriturário e jornalista quando o pai tipógrafo ficou louco. Essas pedras nos caminhos na vida de Lima Barreto são traços marcantes na composição das suas histórias. Lima Barreto fala do seu lugar, de sua condição e das situações que ele tem contato, e coloca essas vivencias em seus romances e contos. Em "Recordações do Escrivão Isaías Caminha”, Isaías Caminha é um jovem de 18 anos, preto, pobre que decide estudar na capital do país; naquele início de República, a capital era a cidade do Rio de Janeiro. A escolarização era algo permitido somente às pessoas brancas, ser uma pessoa letrada significava ser uma pessoa branca, uma das formas que as pessoas negras encontravam de se aproximarem desse ideal branco, era o sonhado diploma de doutor. Lima Barreto narra que a remissão pelo diploma evidenciava não somente a busca pela ascensão social, mas uma tentativa de embranquecimento de Isaias Caminha: "Ah seria doutor! Resgataria o pecado original do meu nascimento humilde, amaciaria o suplício premente, cruciante e onímodo da minha cor..." (BARRETO, 1956, p. 45).

A cor de Lima Barreto e de Isaías não é a cor do pecado; é a do "homem negro, inferno branco, tipo Tarantino." (DJONGA, 2017. https://www.youtube.com/watch?v=0oAq3n8SlMU). São realidades marcadas pela exclusão; é o futuro decidido pela cor da pele. São/é "o homem na estrada" de todo dia, sabem a resposta que é clara e salgada, os mais novos "vive queimando largada", não sabem ler, nem escrever e já sabem o nome da delegada. (DJONGA, 2017. https:// www.youtube.com/watch?v=00Aq3n8SlMU). São os que sonham, assim como Isaías Caminha na viagem a caminho do Rio de Janeiro:

Doutor! Doutor!

Quantos prerrogativas, quantos direitos especiais, quantos privilégios esse título dava! Podia ter dois e mais empregos apesar da 
Constituição: teria direito à prisão especial e não precisava saber nada. Bastava o diploma. (BARRETO, 1956, p. 46).

$\mathrm{O}$ direito à escolaridade sempre foi negado às pessoas negras no Brasil. Inúmeros dispositivos jurídicos impediam negros/as de terem acesso aos bancos escolares. A Constituição de 1824, no artigo 94, inciso II, impedia formalmente o acesso dos/as pretos/as/ aos direitos básicos, como votar e ser votado/a; e também à educação. O Decreto de $\mathrm{n}^{0} 1331$ de fevereiro 1854, proibia os/as negros/as escravizados/as de frequentarem as escolas públicas. Para Gomes (2017), no pós escravidão, a interdição ao direito a educação escolarizada foi uma das principais tecnologias usadas para impedir as pessoas negras de terem acesso ao mercado de trabalho remunerado que se iniciava. O Estado brasileiro institucionalizou o racismo ao negar às pessoas negras o acesso a escolaridade. Essa negação do direito ao saber formal conforme aponta Gomes (2017) reverbera nos dias de hoje, na continuidade dessas políticas que afastam/os/as da escola; e os/as colocam numa enorme disparidade escolar quando comparado com as pessoas brancas.

Mudanças tímidas ocorrem ao longo dos anos. Em 1878, com o Decreto Imperial de $\mathrm{n}^{\mathrm{0}}$ 7031, os negros puderam frequentar o ensino noturno; porém, dependiam da autorização dos "seus" donos. Ao passar dos anos e a partir da luta do movimento negro, homens e mulheres promoveram e consquistaram avanços como a Lei de número 12.288 de 20 de julho de 2010, que insituiu o Estatuto de Igualdade Racial; a Lei $\mathrm{n}^{\mathrm{o}}$ 12.711 de 28 de agosto de 2012, que garantiu direito às cotas raciais no ingresso do ensino superior para pretos/as, pardos/as e indígenas, assim como as Leis 10.639 e a 11.645 que visam a descolonização dos currículos, com a obrigatoriedade do ensino da História e Cultura AfroBrasileira e Indígena. Foram avanços tímidos por conta da enorme dívida do Estado brasileiro com as pessoas negras e indígenas. E mesmo não avançando muito, hoje assisto o avanço das ideias conservadoras que miram sobretudo os parcos direitos do povo preto e indígena. Esses instrumentos jurídicos produzem efeitos e incomodam aqueles/as que são os/as verdadeiros/as privilegiados/as do Estado brasileiro. Que visam manter a estrutura racista, patriarcal, racista, machista, sexista da sociedade brasileira, que coloca o Brasil como um dos países mais desiguais do mundo. País que sequer permite as pessoas negras e indígenas o direito a sonhar.

O sonho de Caminha era a busca da estabilidade na instabilidade da existência que marca a vida de homens e mulheres negros e negras no 
país. Eu cresci sem ter contato com os "doutores" e "doutoras" não brancos/as. Essa não presença, essa não representatividade coloca a pessoa negra numa condição de permanente vigília. Vindo de uma família em que meus pais são semianalfabetos, carrego mesmo que implicitamente no subconsciente os mesmos desejos de Caminha, que eram também os desejos de Lima Barreto.

\section{Ou tu vai ser mais um preto, que passou a vida em branco? (DJONGA, 2019)}

Da viela de uma favela, ele sai bem vestido com uma camisa branca, calça social, sapato bem engraxado, ele é preto, mas usa uma máscara branca. Pele negra, máscaras brancas. O sonho? "tirar seus irmãos da lama, sua coroa larga o trampo, ou tu vai ser mais um preto, que passou a vida em branco?” (Hat-trick, Djonga, 2019. https:// www.youtube.com/results?search_query=hat+trick+clip). A condição do negro é marcada pela necessidade do embranquecimento. A aceitação social no mercado de trabalho, especialmente, é condicionada à negação da sua negrura. Fanon (2008, p. 28) questiona: "Que quer o homem? Que quer o homem negro? Mesmo expondo-me ao ressentimento de meus irmãos de cor, direi que o negro não é um homem." Ao homem negro é reservado o não-lugar, o não-existir, o não existir é existir apenas nas estatísticas criminais. "O negro é um homem negro; isto quer dizer que, devido a uma série de aberrações afetivas, ele se estabeleceu no seio de um universo de onde será preciso retirá-lo" (FANON, 2008, p. 28).

No vídeo clipe da música Hat-Trick (link acima), o rapper Djonga constrói o imaginário do preto que busca ascender socialmente, como Isaías Caminha o desejo, o sonho de mudar a sua condição social, pela alforria do embranquecimento. Pouco antes de partir ao Rio de Janeiro, Isaías Caminha promete a mãe, que assim que se arranjasse, mandaria buscá-la:

Olhe, mamãe, disse eu, logo que me arrume mando-a buscar. A senhora está ouvindo?

__ Sim, respondeu ela com fingida indiferença.

Alugaremos uma casa. Todos os dias, quando eu ir trabalhar, tomarei a sua benção; quando tiver de estudar até alta noite, a senhora há de dar-me café, para espantar o sono... Sim, mamãe? (BARRETO, 1956, p. 48). 
É no subconsciente que guardamos os traumas adquiridos, adverte Freud (2005). A mente humana, na teoria psicanalítica, se divide em três níveis: consciente, pré-consciente e subconsciente. As manifestações do subconsciente vêm à tona em períodos oníricos e também em atos falhos. Para Freud (2005), é comum que haja um certo ceticismo ao afirmar que os sonhos são a vontade de realizar desejos, sobretudo ao se perceber que os conteúdos dos sonhos possuem um caráter aflitivo e, muitas das vezes, fazem a pessoa despertar com uma profunda ansiedade. Porém, ele afirma: "Não se deve esquecer que os sonhos são invariavelmente o produto de um conflito, que eles são uma espécie de estrutura de conciliação.” (FREUD, 1995, p. 191.).

$\mathrm{Na}$ configuração dos sonhos, na perspectiva psicanalítica freudiana há duas maneiras para a formação dos sonhos. Pode ser o resultado de um impulso instintivo, ou seja, um desejo do inconsciente, que durante o sono encontra força para se fazer sentir pelo ego, e também pode surgir do pré-consciente, seria um impulso que restou da vida desperta, atravessado por impulsos díspares, que é reforçado durante a vigília, de algo inconsciente. "Em resumo os sonhos podem originar-se do id ou do ego" (FREUD, 1995, p. 185). O racismo configura um trauma. A psicanálise evidencia que esses traumas são empurrados ao subconsciente e manifestam-se em neuroses que afetam a condição humana. O contato com o irracional, e não há algo mais irracional do que o racismo, conforme relata Fanon (1967, p. 118), é traumático:

Eu fui odiado, desprezado, detestado, não pela vizinha do outro lado da rua ou pelo meu primo por parte de mãe, mas por uma raça inteira. Eu competi contra algo irracional.

Os psicanalistas dizem que nada é mais traumatizante para a criança do que esses encontros com o que é racional. Eu diria, pessoalmente, que para um homem cuja arma é a razão, não há nada mais neurótico do que o contato com o irracional.

\section{Quem tem a minha cor é ladrão. Quem tem a cor de Eric Clapton é cleptomaníaco. (DJONGA, 2019)}

O trem que leva Isaías Caminha desliza pelos trilhos, serpente de aço que atravessa morros e montanhas, meio dormindo, meio acordado ele sonha, com um futuro glorioso. Nunca tivera contato com o racismo, 
já ouvira falar. Mas para quem não vive o racismo, ouvir falar é algo irrisório diante daquilo que realmente é. Numa estação, ao tomar um café e comer um bolo, a realidade mostrou-se para ele. Ao servir-se do desjejum, pagou-o com uma pequena nota. Ao demorarem em trazer-lhe o troco, reclamou por esse. A surpresa foi em ouvir:

"Oh! fez o caixeiro indignado e em tom desabrido. Que pressa tem você?! Aqui não se rouba, fique sabendo?” Ao mesmo tempo a meu lado, um rapaz alourado, reclamava o dele, que lhe foi prazenteiramente entregue. $\mathrm{O}$ contraste feriu-me, e com os olhares que os presentes me lançaram, mais cresceu a minha indignação. Curti durante segundos, uma raiva muda, e por pouco ela não rebentou em pranto. Trôpego e tonto, embarquei e tentei decifrar a razão da diferença dos dois tratamentos. Não atinei; em vão passei em revista a minha roupa e a minha pessoa... (BARRETO, 1956, p. 49).

E continua: "Os esforços que fiz, mais espesso tornaram o capacete plúmbeo que me oprimia o cérebro" (BARRETO, 1956, p. 40). Isaias Caminha não sabe, mas lida com o irracional. $\mathrm{O}$ contato com o branco, formará em sua estrutura psíquica, o homem negro e mostrará que a vida dele "não foi um mar de rosas não." (RACIONAIS Mc's, 1997. https://www.youtube.com/watch?v=fVlT58AIc50).

"Atlanta" é uma série de tv estadunidense, que é veiculada na plataforma de streaming Netflix, criado pelo artista multimídia Donald Glover. Glover usa o nome artístico de Childish Gambino, na série Gambino é Earnest "Earn" Marks, agente do primo Alfred, o "Paper Boi", que abandona a faculdade para agenciar o primo que é um artista emergente de Hip-Hop, na cidade de Atlanta nos EUA.. Em um episódio da segunda temporada, Earn decide gastar o dinheiro que ganhou, uma nota de cem dólares, numa boate. Inútil, ninguém aceita a nota. Suspeitam que seja falsa. O racismo se manifesta no cotidiano, quando a nota de R \$ 100, oo que você homem negro passa no caixa será conferida e re-conferida diversas vezes. É o contato com a irracionalidade do racismo.

O contato com o irracional, colocará Isaías Caminha no estereótipo do bandido. Mesmo que Caminha tente embranquecer, sempre será lembrado que "meu filho, cê num é branco, geral vestido igual, mas os canas te olharam diferente", (FAVELA VIVE 3, 2018. https://www.youtube.com/watch?v=avbOUVHroQI). Um assalto no hotel em que o protagonista do romance está hospedado será o gatilho para que Isaías tenha uma vez mais o contato com o racismo: 
__ E o caso do Jenikalé? Já apareceu o tal "mulatinho"?

Não tenho pejo confessar hoje que quando me ouvi tratado assim, as lágrimas me vieram aos olhos. Eu saíra do colégio, vivera sempre num ambiente artificial de consideração, de respeito, de atenções comigo; a minha sensibilidade, portanto, estava cultivada e tinha uma delicadeza extrema que se juntava ao meu orgulho de inteligente e estudioso, para me dar não que exaltada representação de mim mesmo, espécie de homem diferente do que era na realidade, entre superior e digno a quem um epíteto daqueles feria como uma bofetada. (BARRETO, 1956, p. 49).

É o contato com o preconceito, com a humilhação pela cor da pele. Aqui, mais uma vez, Isaías Caminha tem contato com o irracional, com discriminação e, quando ele se revolta com a forma ultrajante que será tratado como bandido pelo delegado, será jogado numa cela e como restou pouco a ser feito, Isaias relata "As lágrimas correram-me e eu pensei comigo: A pátria.” (BARRETO, 1956, p. 94). As lágrimas correm porque ao negro é negado a existência. Deste prisma, Kilomba (2019, p. 174) afirma:

Esse processo de identificação absoluta - ou essencialismo - no qual uma pessoa é vista meramente como uma "raça" (grifo da autora) é somente possível porque no racismo nega-se, para negras e negros, o direito à subjetividade.

Kilomba (2019) fala da palavra e do trauma construído por meio do recurso discursivo. A palavra "mulatinho" é adocicada por meio do diminutivo. Essa infantilização é usada como forma de camuflar o racismo, é um jogo de palavras que toma o diminutivo para verbalizar as inúmeras faces do racismo à brasileira. "É discursivo e não biológico; funciona através do discurso, através de uma cadeia de palavras e imagens que se tornam associativamente equivalentes, mantendo identidades em seu lugar" (KILOMBA, 2019, p. 156-157).

Ser nomeado de mulatinho é ser negado na sua existência, pois a palavra mulato remete ao substantivo mula, ou mulo, etimologicamente que dizer animal híbrido, estéril, fruto do cruzamento do cavalo com a jumenta, ou da égua com o jumento. Isaias Caminha é então o mulatinho, ao passo que Clara dos Anjos será a "mulatinha". Claras dos Anjos, romance concluído em 1922, mesmo ano da morte de Lima Barreto é uma denúncia áspera do preconceito racial e social vivenciando por uma jovem mulher do subúrbio carioca. A condição feminina também fará parte desse relato: uma formação machista, superprotetora, 
repressiva e limitadora reservada à Clara dos Anjos que "quis ser chamada de morena, que isso camufla o abismo entre e a humanidade plena." (EMICIDA, 2019. https://www.youtube.com/watch? $\mathrm{v}=4 \mathrm{pBp} 8 \mathrm{hRmynI}$ ).

Clara dos Anjos não existe, é apenas um acessório na vida patriarcal, "O seu ideal na vida não era adquirir uma personalidade, não era ser ela, mesmo ao lado do pai ou do futuro marido. Era constituir função do pai, enquanto solteira, e do marido, quando casada”. Barreto (1995, p. 112). Clara é uma mulata pobre, que vive no subúrbio carioca com seus pais, Joaquim e Engrácia, mulher sedentária e caseira. Joaquim é carteiro de profissão apaixonado por modinhas e tinha devoção pelo instrumento musical violão. Observem, no trecho transcrito, como apenas Joaquim tem identidade, tem uma função social, ao contrário de Clara e Engrácia. A esse respeito, Kilomba (2019, p. 190) relata:

Mulheres negras, por não serem nem brancas nem homens, passam a ocupar uma posição muito difícil dentro de uma sociedade patriarcal de supremacia branca. Nós representamos um tipo de ausência dupla, uma Outridade dupla, pois somos a antítese tanto da branquitude, quanto da masculinidade.

A literatura insurgente de Lima Barreto é um rompimento com as regras canônicas de escrita literária da época. O escritor abandona o modo artificial e erudito de escritura. A idiossincrasia da escrita limabarretiana é marcada pela informalidade no estilo, uma das características do jornalismo e da oralidade, da prosa cotidiana, em que as frases muitas das vezes saem soltas e descontraídas. "O carteiro era pardo-claro, (tentativa de embranquecimento, grifo meu), mas com cabelo ruim, (idem) como diz; a mulher, porém, apesar de mais escura, tinha o cabelo liso." (BARRETO, 1995, p. 50).

Como Lima Barreto compõe a estética da protagonista Clara dos Anjos na obra de mesmo nome? Como ela mesmo se vê e como essas relações cor-da-pele-cabelo são tratadas nas questões do racismo cotidiano? "Na tez, a filha tirava o pai; no cabelo, à mãe." Barreto (1995, p. 50). Clara é objetificada na condição de mulher negra, essa situação é essencial no enredo do romance, sobretudo, pela forma com que Cassi Jones é retratado, como sendo "um rapaz de pouco menos de trinta anos, branco, sardento.” (BARRETO, 1995, p. 25). 


\section{Cada vez mais objetivo, pra que minhas irmãs deixem de ser objeto (DJONGA, 2019)}

Kilomba (2019) fala das políticas de pele e da necessidade de se discutir a questão da mulher negra na sociedade. Ela denuncia como as pessoas negras são fantasiadas como negativas no inconsciente branco e fala da necessidade de rejeitar essas fantasias. Questões ligadas à hiperssexualização e à objetificação dos corpos negros são levantadas pela autora supracitada. Mitos como da mulher negra que tem a vagina quente são a representação dessas hiperssexualizações e objetificações do corpo da negra. São as intersecções entre racismo e machismo que atravessam a vida de Clara, assim como das mulheres pretas, "minhas irmãs, mais que empoderada e sim poderosa, cês ainda não entenderam a diferença da buceta que dá vida para um pau que goza.”, https:// www.youtube.com/watch?v=NGfPtLxIzpc) (DJONGA, 2018). (Essed, 1991; hooks, 1989) apud Kilomba (2019, p. 98-99) evidencia que "Formas de opressão não operam em singularidades; elas se entrecruzam. O racismo, por exemplo, não funciona como ideologia e estrutura distintas; ele interage com outras ideologias e estruturas de dominação como o sexismo.”

As mulheres pretas são tratadas como um pedaço de carne, até mesmo em maternidades, especialmente as públicas, de onde surgem relatos de mulheres que têm o útero retirado, retrato da violência que não apenas viola o corpo, mas a própria alma. Clara dos Anjos será marcada por essa realidade, ao ser deflorada por Cassi Jones.

Mas afinal quem é Cassi Jones? Ele é o filho legítimo de Manuel Borges de Azevedo e Salustiana Baeta de Azevedo. Cassi é a antítese de Clara: sedutor, branco, sardento e de cabelos claros. E usa essa estética para assediar as criadas que prestavam serviços em sua casa. Aqui, Lima Barreto continua narrando a própria formação da sociedade brasileira, que romantizou o estupro, a violação da dignidade e integridade das mulheres negras. Fato consentido pela própria mulher branca, que internalizada numa sociedade patriarcal, machista e sexista, assume posições como a da dona Salustiana, mãe de Cassi Jones. Diante dos relatos das moças negras defloradas por Cassi:

A mãe recebia-lhe a confissão, mas não acreditava; entretanto, como tinha as suas presunções fidalgas, repugnava-lhe ver o filho casado com uma criada preta, ou com uma pobre mulata costureira, ou com uma moça branca lavadeira e analfabeta. (BARRETO, 1995, p. 26) 
É dessa condição que Engrácia tenta salvar a filha, um destino inelutável que marca as vidas das mulheres como Clara dos Anjos. Mais uma vez, a interseccionalidade é necessária para fazer a análise das relações de gênero e raça, que no Brasil manifestam-se na precocidade da iniciação sexual por parte das adolescentes negras. Dados do (IBGE, 2012), em reportagem do jornal Folha de S. Paulo (https:// www1.folha.uol.com.br/cotidiano/2018/o7/desigualdade-pela-renda-ecor-da-pele-e-exposta-em-abortos-de-riscos-no-pais.shtml), apontam que os números de jovens negras grávidas é superior ao número de adolescentes brancas grávidas, considerando as idades entre 12 e 18 anos. A gravidez na adolescência ocasiona também a evasão escolar e perpetua o ciclo de pobreza da mulher negra. $O$ índice de jovens negras que abandonam a escola depois de uma gravidez é maior na comparação com as jovens brancas. São meninas mulheres que "nem sapato tem, a maioria de barriga cheia, quem dera fosse de comida, é a mãe do filho de um membro do trem." (FAVELA VIVE 3, 2018).

Pobreza, raça e gênero são interseccionalidades que operam na realidade do racismo cotidiano. São interseccionalidades difíceis de serem superadas. A união com Cassi Jones é para Clara dos Anjos a saída romantizada da sua condição de mulher negra:

Uma dúvida lhe veio; ele era branco; e ela mulata. Mas que tinha isso? Havia tantos casos... Lembra-se de alguns... E ela estava tão convencida de haver paixão sincera no valdevinos, que, ao fazer esse inquérito, já recolhida, ofegava, suspirava, chorava, e os seus seios duros quase estouravam de virgindade e ansiedade de amar. (BARRETO, 1995, p. 67)

"Mas abre o olho com as novinhas, estão achando que se cuidar é só usar camisinha, abre o olho da sua novinha, nove meses depois eu já sei quem não vão assumir, adivinha?" (DJONGA, 2017. https:// www.youtube.com/watch?v=oJZqQIa8h4M). Esquimó é uma música que toda mãe preta deveria ouvir com as filhas e com os filhos; a luta contra o machismo passa pelas mães, parafraseado Ângela Davis, negra, ativista, militante da luta pelo direitos civis dos negros estadunidenses, black panther, numa sociedade machista, não basta não ser machista é preciso lutar contra o machismo, "todos devem ser feministas". Esquimó, do rapper Djonga, é um desses gritos contra o machismo.

Clara dos Anjos cedera às investidas de Cassi Jones, ele tirara-lhe a virgindade. De acordo com Beauvoir (1980, p. 110), é: 
Pela vagina que a mulher é penetrada e fecundada; e a vagina se torna centro erótico pela intervenção do homem e essa intervenção constitui sempre uma violação. Por um rapto real ou simulado é que a mulher era outrora arrancada de seu universo infantil e jogada na sua vida de esposa; é uma violência que a faz passar de moça à mulher: diz-se também "tirar" a virgindade de uma jovem, "tomar-lhe" a flor. Essa defloração não é o fim harmônico de uma evolução contínua, é a ruptura abrupta com o passado, o início de um novo ciclo.

Cassi a deflorou, "Por que a escolhera? Porque era pobre e, além de pobre, mulata.” Barreto (1996, p. 161).

\section{É triste ver que os muleke da minha quebrada não teve a mesma sorte que eu, um pai presente, no país onde é o homem que aborta mais, vai entender né... (DJONGA, 2019)}

A situação ficcional de Clara é a situação real das milhares de Claras, Anas, Marias que são "daquela cor que só serve pra ser abusada” (DJONGA, 2019.) (https://www.youtube.com/watch? $\mathrm{v}=$ bsEwoOYGfiU). São meninas mulheres que criam os filhos sozinhas, são abandonadas pelos pais de seus filhos ou têm os companheiros mortos pela política de extermínio da juventude negra que mata homens, jovens e pretos, moradores das periferias das cidades brasileiras.

Pensou em morrer; pensou em se matar; mas, por fim chorou e rogou a Nossa Senhora que lhe desse coragem. Se pudesse esconder?... Acudiu-lhe repentinamente este pensamento. Se pudesse "desfazê-

lo"? Seria um crime, havia perigo de sua vida; mas era bom tentar. (BARRETO, 1995, p. 155)

Beauvoir (1980) fala que a maternidade ilegítima configurava, na França do século XIX uma tara horrível, o que fazia com que muitas preferissem o suicídio ou o infanticídio à condição de mãe solteira. A interrupção terapêutica da gravidez é uma condição imposta às mulheres. O relatório do Ministério da Saúde, divulgado em reportagem do jornal Folha do S. Paulo (https://www1.folha.uol.com.br/cotidiano/ 2018/o7/desigualdade-pela-renda-e-cor-da-pele-e-exposta-em-abortosde-riscos-no-pais.shtml), aponta que as interseccionalidades de cor, renda e escolaridade são determinantes na vida e na morte das mulheres que buscam medidas como aquela. De acordo com os dados do relatório, 
que mapeou os gastos do SUS (Sistema Único de Saúde) entre os anos de 2008 a 2017, com as interrupções terapêuticas da gravidez, a taxa de óbitos causados por essas interrupções: a cada 100 mil nascidos vivos é de 3 entre a mulheres brancas; número que sobe para 5 se a mulher for negra. A interrupção voluntária da gravidez é muitas das vezes conseguida por técnicas caseiras e perigosas, usadas principalmente pelas pretas, pardas e pobres. "Quem lhe ensinaria o remédio? Correu o rol de suas poucas amigas e só encontrou uma: Dona Margarida." (BARRETO, 1995, p. 162). Beauvoir (1980) relata que, na França do século XIX, empregava-se técnicas como a do "gancho" ou mesmo comprimidos dados pelas "fazedoras de anjos".

E continua relatando que nas cidades as mulheres criam redes de apoio mútuo; a mulher grávida solicita apoio à amiga ou, em alguns casos, ela mesma realiza o procedimento. Perfuram-se com agulhas de tricô ou ganchos. Há casos em que são introduzidos no útero vinagres e outros líquidos com intuito de provocar a interrupção da gravidez. Essas "soluções caseiras" provocam "Graves moléstias internas e podem desencadear uma hemorragia mortal.” (BEAUVOIR, 1980, p. 254).

\section{Se você não liga, não entendeu nada... (FLORA MATOS, 2017)}

Ao procurar D. Margarida, Clara dos Anjos espera ajuda para fazer a interrupção da gravidez; porém, essa a demove da ideia, conta a situação à mãe de Clara e as três decidem procurar a família de Cassi Jones. Quem as recebe é D. Salustiana, mãe de Cassi, e qual o desejo da moça? “_ Que se case comigo.” (BARRETO, 1995, p. 171). Em que a mãe do jovem responde: “—Que é que você diz, sua negra?". E prossegue:

_ Casado com gente dessa laia...Qual! Que diria meu avô, Lord Jones que foi cônsul da Inglaterra em Santa Catarina - que diria ele, se visse tal vergonha? Qual!...__engraçado, essas sujeitas! Queixam-se de que abusaram delas... É sempre a mesma cantiga... Por acaso, meu filho as amarra, as amordaça, as ameaça com faca e revolver? Não. A culpa é delas, só delas...

A culpa é delas, só delas, frases, construções que estão presentes para evidenciar o machismo que atravessa a sociedade patriarcal, machista e sexista brasileira. Por toda sua literatura insurgente, de uma 
forma ou de outras, Barreto evidenciou as manifestações explícitas de racismo na sociedade, inúmeras formas de preconceito racial que oprimem e marginalizam os/as negros/as. Recordações do Escrivão Isaías Caminha e Clara do Anjos não fogem desse propósito. São romances que denunciam a situação dos/as pretos/as no início do século XIX, conjuntura não muito diferente de hoje. condição:

As palavras de Clara no final do romance são o retrato dessa

__Mamãe, Mamãe!

_Que é minha filha?

_ Nós não somos nada nesta vida. (BARRETO, 1995, p. 171)

Clara, a negra seduzida e abandonada pelo namorado branco é a primeira personagem da letra insurgente de Lima Barreto; é por meio dela que ele denuncia o racismo sofrido pelos/as negros/as e pobres brasileiros/as. Numa sociedade em que a injustiça social e os racismos em suas múltiplas faces reverberam de forma estrondosa, muitas mulheres pretas estão fatalmente sentenciadas ao mesmo destino de Clara. Clara "quis ser chamada de morena que isso camufla o abismo entre si e a humanidade plena" (Ismália, AmarElo, 2019.https:// www.youtube.com/watch?v=4pBp8hRmynI), afinal "não somos nada nesta vida."

Afinal, foi o que eles quiseram nos ditar por anos, que não somos nada nesta vida. Essa foi a condição imposta tanto a Isaías Caminha, quanto a Clara dos Anjos. Essa é a condição imposta a milhões de pessoas negras no Brasil. Do tratamento desumano à categoria de coisas, de mercadoria, de algo para ser usado; Clara e Isaías são a letra insurgente de Lima Barreto para denunciar a condição do homem e da mulher negra no início do século XIX, condição que continua a se impor século XXI, condicionando e cerceando o direito de sermos tudo o que quisermos ser nessa vida.

\section{Gente que acredito, gosto e admiro (RACIONAIS' MC, 2002)}

AKOTIRENE, Carla. Interseccionalidade. São Paul, SP: Sueli Carneiro; Polén, 2019. 152 p. 
ATLANTA. 2 temporadas Netflix. EUA. 2016

COLLUCCI, Cláudia. BARBON, Júlia. Desigualdade pela renda e cor da pele é exposta em abortos de risco no país. Folha de S.Paulo, São Paulo e Rio de Janeiro, 29 de jul. de 2018. Disponível em: < https:// www1.folha.uol.com.br/cotidiano/2018/07/desigualdade-pela-renda-ecor-da-pele-e-exposta-em-abortos-de-riscos-no-pais.shtml >. Acesso em: 12 jan. 2020.

BARRETO, Lima. Clara dos Anjos. São Paulo: Editora Ática. 1995.

BARRETO, Lima. Recordações do escrivão Isaías Caminha. São Paulo, Brasiliense, 1956.

BEAUVOIR, Simone. O Segundo Sexo: A Experiência Vivida. Rio de Janeiro: Ed. Nova Fronteira,1980.

CANDIDO, Antônio. $O$ direito à literatura. In: - Vários escritos. 3. ed. São Paulo: Duas Cidades, 1995.

CERTEAU, Michael: A Invenção do Cotidiano. Petrópolis-Rj: ed. Vozes, 1998.

DEULEZE, Gilles; GUATTARI, Felix. O que é Fỉlosofia? São Paulo: Editora 34, 2010.

DIVERSOS. Favela Vive 3. Disponível em: < https://www.youtube.com/ watch?v=avbOUVHroQI $>$ Acesso em: 17 jan. 2020.

DJONGA. O mundo é nosso. Disponível em: < https:// www.youtube.com/watch?v=hTUEjPmXotE > Acesso em: 16 jan. 2020.

DJONGA. Hat-trick. Disponível em <https://www.youtube.com/ results?search query=hat+trick+clip > Acesso em: 16 jan. 2020.

DJONGA. (Feat Carol Conka). Estouro. Disponível em: <https:// www.youtube.com/watch?v=NGfPtLxIzpc $>$ Acesso em: 18 jan.2020.

DJONGA. Esquimó. Disponível em <https://www.youtube.com/watch? $\mathrm{v}=0 \mathrm{JZqQIa} 8 \mathrm{~h} 4 \mathrm{M}>$ Acesso em: 18 jan. 2020.

DJONGA. Bença. Disponível em <https://www.youtube.com/watch? $\mathrm{v}=$ bsEwoOYGfiU $>$ Acesso em: 18 jan. 2020. 
EMICIDA. Esmália, AmarElo. Disponível em: <https:// www.youtube.com/watch?v=4pBp8hRmynI $>$ Acesso em: 15 jan. 2020.

ESTARQUE, Marina. Cresce a proporção de bebês nascidos de adolescentes na periferia. Folha de S. Paulo, São Paulo, 27 de mai. De 2019. Disponível em: https://www1.folha.uol.com.br/cotidiano/ 2019/05/cresce-proporcao-de-bebes-nascidos-de-adolescentes-naperiferia-de-sp.shtml >. Acesso em: 12 jan. 2020.

FANON, Frantz. Pele negra, máscaras brancas. Bahia: Editora Edufba, 2008.

FLORASMATOS. Autoditada. Disponível em: <https:// www.youtube.com/watch?v=92jEmOnilMQ> Acesso em: 15 jan. 2020.

FREUD, Sigmund Freud. As cartas de Sigmund Freud para Eduard Silberstein. Rio de Janeiro: Imago, 1995.

GOMES, Nilma Lino. O movimento negro educador. Saberes construídos na luta por emancipação. Petrópolis, RJ: Vozes, 2017.

hooks, bell. Talking back: thinking feminist, thinking black. Boston: South End Press, 1989.

KILOMBA, Grada. 1968 - Memorias da Plantação: Episódios de Racismo Cotidiano? Trad. Jess Oliveira. Rio de Janeiro: Cobogó, 2019.

MAKONI, Sinfree; PENNYCOOK, Alastair. (Ed.). Disinventing and reconstituting languages. Clevedon: Multilingual Matters, 2007.

MARX, Karl; ENGELS, Friedrich. A Ideologia Alemã. Trad. Castro e Costa, L. C. São Paulo: Martins Fontes, 2002.

PENNYCOOK, Alastair (2006) Uma linguística aplicada transgressiva. In: Moita Lopes, Luiz Paulo (Org).

RACIONAIS MC'S. Um homem na estrada. Disponível em < https:// www.youtube.com/watch?v=fVlT58AIc50 > Acesso em: 18 jan. 2020. 


\section{Interseccionalidades de Raza, Género, Machismo y Sexismo en la Literatura Insurgente de Lima Barreto}

RESUMEN: Este texto es un viaje literario, musical, pop, idiosincrásico y subrepticio a través de un camino que busca mis subjetividades con dos obras literarias de la escritora Lima Barreto: Clara dos Anjos; Memorias del Registrador Isaías Caminha. Lo hago con la ayuda de Kilomba (2019), Beauvoir (1980), hooks (1989), Cândido (1995), Fanon (2008), Freud (1995), entre otros. Busco colocar la literatura limabarretiana en el campo de la literatura insurgente, escritos que rompen con lo canónico e insurgente contra los dogmas actuales. Escritura insurgente, mi ensayo se presenta como un desafío para construir nuevas posibilidades en la escritura académica, por lo que elijo configurarlo en un lenguaje caleidoscópico e intersectado, analizando y problematizando varios temas que están fragmentados en recortes específicos, y se unen para formar un todo que representa la unidad muy idiosincrásica de los sujetos y los "sujetos" presentes en las referencias teóricas que anclan el texto. Las partes del ensayo forman el todo y el todo forma las partes, por lo que la escritura funciona como un flujo de pensamiento en el que no hay principio ni final, una conclusión. Inserto en el cuerpo del texto los enlaces de las canciones citadas para que el lector experimente una lectura semiótica de la investigación, alternando la lectura con la escucha / visualización de / de las canciones / clips.

PALABRAS ClaVE: Literatura. Racismo. Machismo. Sociedad.

Edergênio Negreiros VIEIRA

Professor efetivo da rede municipal de ensino do Município de AnápolisGoiás, atuando na educação básica. Formação em Letras Português Brasileiro e Língua Inglesa; e Pedagogia ambas pela Universidade Estadual de Goiás. Pós graduação Lato Sensu em Linguagem e Educação Escolar também pela Universidade Estadual de Goiás. Militante do movimento negro e dos direitos humanos, poeta, articulista do Blog Cartas Proféticas. Mestrando do Programa de Pós Graduação em Educação, Linguagem, e Tecnologias da Universidade Estadual de Goiás - PPG-IELT. 